\title{
Improving Test-Taking Effort in Low-Stakes Group-Based Educational Testing: A Meta-Analysis of Interventions
}

\author{
Joseph A. Rios \\ University of Minnesota
}

\begin{abstract}
Author's Note
The author would like to thank Blair Lehman, Lydia Liu, Jennifer Bochenek, Elizabeth Stone, Brent Bridgeman, and Cristina Anguiano Carrasco from the Educational Testing Service for their comments on an earlier draft as well as Bradley Hartwyk from the University of Minnesota for his assistance with coding.
\end{abstract}

Correspondence concerning this article should be sent to Joseph A. Rios, University of Minnesota, 56 E River Rd, Minneapolis, MN 55455

Email: jrios@umn.edu

\section{Cite as:}

Rios, J. A. (2021). Improving test-taking effort in low-stakes group-based educational testing: A meta-analysis of interventions. Applied Measurement in Education. Advanced online publication. https://doi.org/10.1080/08957347.2021.1890741 


\begin{abstract}
Four decades of research have shown that students' low test-taking effort is a serious threat to the validity of score-based inferences from low-stakes, group-based educational assessments. This meta-analysis sought to identify effective interventions for improving students' test-taking effort in such contexts. Included studies (a) used a treatment-control group design; (b) administered a low-stakes group-based educational assessment; (c) employed an intervention to improve testtaking motivation; (d) evaluated test-taking effort and/or test performance as outcomes. The analysis included 53 studies $(\mathrm{N}=59,096)$ that produced 60 and 105 effect sizes of test-taking effort and test performance, respectively. On average, interventions were found to improve testtaking effort and test performance by 0.13 standard deviations $(S D)$ each. The largest gains in test-taking effort were observed when providing external incentives followed by increasing test relevance, while no significant differences were found between these two intervention types in improving test performance. Furthermore, negligible impact was detected on both dependent variables for interventions that modified assessment design or promised feedback. Recommendations for future research and practice are discussed.
\end{abstract}

Keywords: meta-analysis, test taking, motivation, low-stakes testing, educational assessment 


\section{Improving Test-Taking Effort on Low-Stakes Group-Based Educational Assessments:}

\section{A Meta-Analysis of Interventions}

Group-based educational assessments (e.g., standardized tests used in U.S. public schools associated with the Elementary and Secondary Education Act of 1965; the National Assessment of Educational Progress [NAEP]; the Programme for International Student Assessment [PISA]) have been implemented within the United States and across the world for well over fifty years to benchmark students' performance and improve achievement. Such large-scale assessments have provided significant information for policymakers, educators, and researchers domestically and globally in terms of identifying students' strengths and weaknesses, studying trends, and promoting effective practices. Although the results from such assessments have important implications for schools and districts, as well as state and national departments of education, individual test takers typically bear minimal consequences for their performance (i.e., the assessment is low-stakes for students). This testing context stands in stark contrast to high-stakes assessments (e.g., college admissions tests) where results can potentially have life-altering personal implications. ${ }^{1}$ The lack of personal consequences associated with low-stakes assessment results raises the concern of whether students are fully engaged or expend maximum energy toward the goal of attaining their highest possible test score (i.e., put forth adequate testtaking effort; Wise \& DeMars, 2005). If not, scores may not accurately reflect the skills, proficiencies, and/or abilities being assessed (Eklöf, 2010), which could lead to providing stakeholders with misleading information about student learning (American Educational

\footnotetext{
${ }^{1}$ As a result of the important personal consequences for students associated with high-stakes assessments, it is assumed that individuals will put forth maximal effort due to increased perceived value. Consequently, the interventions examined and the inferences drawn from the results in this paper are not expected to be of use in highstakes testing contexts.
} 
Research Association [AERA], 2000; AERA, American Psychological Association, \& National Council on Measurement in Education, 2014; Baker et al., 2010).

Given the concern of making accurate inferences from low-stakes assessments, it is critical for practitioners to become aware of strategies that can help boost students' test-taking effort. To that end, I conduct a meta-analysis of test-taking effort interventions from elementary through postsecondary education settings. I include studies that (a) used a treatment-control group design; (b) administered a low-stakes group-based educational assessment; (c) employed an intervention to improve test-taking motivation; (d) evaluated test-taking effort and/or test performance as outcomes. In the sections that follow, I elaborate on how low test-taking effort could become a threat to the validity of score-based inferences, discuss the types of interventions researchers have proposed to mitigate low test-taking effort, summarize previous meta-analyses associated with test-taking effort, and discuss the needs for the current meta-analysis.

\section{Low Test-Taking Effort as a Threat to the Validity of Score Interpretation}

A useful theoretical framework for representing student test-taking behavior is provided by the expectancy-value theory of achievement motivation (Wise \& DeMars, 2005).

According to this theory, test-taking effort is impacted by how well an individual believes that they will perform on the assessment (expectancy of success) ${ }^{2}$ and the value associated with the assessment task (task value; Penk \& Schipolowski, 2015; Pintrich \& Schunk, 2002). The latter can be separated into four components, which consist of (a) a desire to perform well on; (b) the subjective interest in; (c) the utility or extrinsic value associated with; (d) the perceived amount

\footnotetext{
${ }^{2}$ Although expectancy of success is theorized to impact test-taking effort, to the best of the author's knowledge, the only study to have investigated this relationship was conducted by Penk and Schipolowski (2015). They found that expectancy of success was a significant predictor of effort both before $(\beta=0.13, p<.05)$ and after $(\beta=0.16, p<$ .05 ) test administration, however, its effect was far weaker than the direct effect of value on effort (Before: $\beta=0.68$, $p<.05$; After: $\beta=0.66, p<.05)$.
} 
of resources required to complete the task (Eccles \& Wigfield, 2002; Wigfield \& Eccles, 2000).

Previous research has shown that across student populations, when assessment results have no personal consequences, test-takers tend to place little subjective value on the assessment task, which results in decreased test-taking effort, and ultimately an underestimation of student performance (e.g., Cole, Bergin, \& Whittaker, 2008; Penk \& Schipolowski, 2015; Sundre, 1999; Sundre \& Kitsantas, 2004; Wolf \& Smith, 1995). This assertion has been supported by a metaanalysis conducted by Wise and DeMars (2005) in which 12 studies (ranging in year of publication from 1947 to 1999) were evaluated for performance differences by test stakes (high versus low). They found that across 25 effect sizes, test-takers in high-stakes assessment contexts scored on average 0.59 standard deviations $(S D)$ higher than individuals in low-stakes contexts. As a result of these large performance differences, it is of no surprise that low test-taking effort has been found to lead to biased (a) treatment effects (e.g., Osborne \& Blanchard, 2011; Liu, Rios, \& Borden, 2015); (b) achievement gains (e.g., Wise \& DeMars, 2010); (c) value-added estimates of teacher effectiveness (Williams, 2015; Wise, Ma, Cronin, \& Theaker, 2013); (d) country-level comparisons (e.g., Debeer, Buchholz, Hartig, \& Janssen, 2014; Goldhammer, Martens, Christoph, \& Lüdtke, 2016). From these results, it is clear that a failure to ensure adequate test-taking effort may lead to both inaccurate score-based inferences and, possibly, inaccurate consequential decisions related to educational stakeholders (e.g., school staff and/or education systems).

\section{Implementing Interventions to Improve Test-Taking Effort}

Motivating academically unmotivated students has long been a concern within the education field (Hidi \& Harackiewicz, 2000; Lazowski \& Hulleman, 2016). One approach to addressing motivation issues within the educational testing context is to manipulate students' 
effort via an intervention with the goal of obtaining a more accurate estimation of their true ability. To this end, four broad categories of strategies have been proposed (Wise \& DeMars, 2005), including (a) increasing test relevance; (b) modifying assessment design; (c) promising feedback; (d) offering external incentives. Each one of these strategies is described in further detail below.

Increasing test relevance. One simple approach to increase students' subjective value of assessments, and therefore increase test-taking effort, is to raise the personal consequences of assessment results for test-takers (e.g., associating test scores with course grades). However, as noted by Wise and DeMars (2005), such a strategy presents two major challenges. For one, test security may be a greater concern as some students may be more apt to cheat on the assessment due to the elevated stakes. This, in turn, will require greater resources to develop more items and test forms for test security purposes as well as heightened test administration procedures (U.S. Department of Education, 2013). The second major challenge is that high-stakes assessments may be perceived to cause debilitating test anxiety, and in some cases, illness in students (Bennett, 2016). Clearly, such a perceived outcome can lead to resistance from multiple stakeholders (e.g., students, parents, school personnel), which thwarts the feasibility of this intervention type. To overcome these challenges, some researchers have suggested that an alternative to raising the test stakes is to increase the personal relevance of the assessment results for test-takers via test instructions (e.g., Baumert \& Demmrich, 2001; Finney, Sundre, Swain, \& Williams, 2016; Hawthorne, Bol, Pribesh, \& Suh, 2015; Kornhauser, Minahan, Siedlecki, \& Steedle, 2014; Liu, Bridgeman, \& Adler, 2012; Liu et al., 2015; Wise, 2004). As an example, previous strategies have involved highlighting the importance of the assessment results in improving classroom instruction, curriculum, and institutional reputation. By doing so, the hope 
is that students will understand the importance of the assessment for the educational institution and staff even though the results have no personal consequences for themselves.

Modifying assessment design. Previous research has found that students' test-taking effort is greater when given items that are (a) not too mentally taxing (i.e., items possessing a minimal number of words and selected-response items rather than open-ended items; DeMars, 2000; Sundre, 1996; Wise, 2006; Wise, Pastor, \& Kong, 2009; Wolf, Smith, and Birnbaum, 1995); (b) of moderate difficulty (Pintrich \& Schunk, 2002); (c) intrinsically interesting to students (Attali \& Arieli-Attali, 2015). These findings have prompted researchers to modify assessment design in a number of ways. As an example, it has been suggested that test developers should avoid lengthy item stems, minimize the number of response options, and limit the number of open-ended items included on the assessment to decrease the perception that items are too mentally taxing (Wise, 2006; Wise et al., 2009). In a similar vein, to avoid students either becoming frustrated or disengaged due to the perception that items are either too easy or difficult, researchers have proposed employing computer adaptive testing (CAT) in which administered items are matched to test-takers' abilities. There has also been a call to make the assessment itself more appealing for students by providing content that aligns with the interest of test-takers (Wise, 2014), including the name of students in the item stem (Kosh, 2017), as well as employing game design features in the assessment context (Attali \& Arieli-Attali, 2015). Clearly, these proposals will require practitioners to think more critically about test-taking effort early in the test development process, but by altering the assessment design, students' effort may be improved.

Promising feedback. An additional strategy to increase test-taking effort on low-stakes assessments is to provide students with performance feedback in regards to performance, 
improvement, and use of the assessment results (Wise \& Smith, 2016). This strategy builds off of previous research findings that suggest students' intrinsic motivation can be increased by providing performance-contingent feedback that is perceived by students to be informative of their competence (Harackiewicz, Manderlink, \& Sansone, 1984; Ryan, Mims, \& Koestner, 1983). Furthermore, students have reported wanting to know how they perform on low-stakes assessments (Wise, 2004). These two findings have prompted Sundre, Erb, and Russell (2009) to claim that reporting feedback to students as a means of improving their test-taking effort is a “win-win" situation for both test administrators and students. However, merely providing feedback does not guarantee that test-taking effort will be improved (e.g., Baumert \& Demmrich, 2001; Wise, 2004); instead, positive effects may largely be due to both the quality (Wise \& DeMars, 2005) and timeliness (immediacy) of the feedback (Hattie \& Timperley, 2007). To this end, increased research has focused on making feedback accessible and easy to understand, providing evidence to support feedback credibility, leveraging technology (e.g., automated scoring) to improve the timeliness of assessment results, and delivering feedback that is more detailed than that reported at the general subject area level (i.e., summative and normative information) for the purpose of informing preparation for future test administrations (e.g., Coe, 1998; Marsh, Pane, \& Hamilton, 2006). If quality feedback can be provided, this intervention strategy will require additional planning and resources (Wise \& DeMars, 2005). In turn, it has the potential to improve future test performance (Muralidharan \& Sundararaman, 2010), which students may see as being beneficial.

Providing external incentives. In an attempt to strengthen the utility value of low-stakes assessments, researchers have suggested providing external incentives to students for test performance. This approach builds off previous work that has shown that providing students 
rewards associated with specified standards of excellence for success in academic tasks leads to increased effort, greater persistence, and enhanced achievement (Bandura, 1977, 1993; Schunk, 1984). In reference to test-taking effort, these findings indicate that offering test-takers tangible rewards, such as contingent-based monetary incentives or performance-based academic awards (e.g., certificate of proficiency), has the potential to increase both the utility and attainment value associated with the assessment (Baumert \& Demmrich, 2001; Wise \& DeMars, 2005). In a metaanalysis of 46 independent samples $(n=2,008)$, Duckworth, Quinn, Lynam, Loeber, and Stouthamer-Loeber (2011) found that the mean effect of material incentives (e.g., money and candy) on intelligence quotient (IQ) scores was $0.64 S D(95 \% \mathrm{CI}:=0.39,0.89, p<.001)$ with particularly strong effects being noted for low ability test-takers. Although providing incentives has been found to be successful with IQ cognitive ability test scores in a low-stakes research environment, it is unclear whether it is also effective for low-stakes educational achievement assessments.

\section{Need for a Synthesis of Interventions for Improving Test-Taking Effort}

Although multiple strategies have been suggested for promoting students' test taking effort, it is unclear which intervention features and contextual variables (e.g., demographic attributes of study participants, test content, characteristics of the outcome measures) are associated with positive outcomes. Such an understanding would require a synthesis of previous research; however, at the time of this writing, there have been few syntheses related to testtaking effort. Specifically, Wise and DeMars (2005) conducted a meta-analysis to evaluate whether test-stakes impact test performance and, as noted, Duckworth et al. (2011) synthesized research findings to investigate the influence of external incentives on IQ test performance. Neither one of these syntheses compared the effectiveness of multiple strategies for improving 
test-taking effort nor did they focus solely on the context of low-stakes educational assessments. Consequently, it is unknown how many studies have implemented test-taking effort interventions, the mechanisms employed to manipulate test-taking effort, their overall effect, or the role that contextual variables play in impacting study outcomes. Knowing this information may provide practitioners with guidelines on how to best address issues of test-taking effort so as to minimize its deleterious effect on the validity of score-based inferences obtained from lowstakes educational testing contexts.

\section{Study Objectives}

The purpose of this paper is to fill the gap in the literature by conducting a meta-analysis of studies that include interventions to improve test-taking effort and performance in low-stakes group-based educational testing contexts (both locally-developed and large-scale assessments). Such a project is vital as extensive research efforts have been placed predominantly on controlling for low test-taking effort via post-hoc analyses, such as filtering careless responses (e.g., Rios, Guo, Mao, \& Liu, 2017; Rios, Liu, \& Bridgeman, 2014) or incorporating measures of test-taking effort into IRT ability estimation (e.g., Wise \& Kingsbury, 2016). However, as noted by Rios et al. (2017), the most effective approach may be dealing with test-taking effort before it becomes an issue, particularly as there are a number of limitations associated with post-hoc methodologies (e.g., some procedures for filtering careless responses due to low test-taking effort may actually bias aggregated-scores; Rios et al., 2017). In addressing the study objective, the following research questions were evaluated:

1. What is the overall impact of interventions on improving test-taking effort and test performance on low-stakes group-based educational assessments? 
2. What are the contextual variables (e.g., participant, methodological, and assessment characteristics) that moderate the impact of such interventions?

3. Which intervention type is most effective in improving test-taking effort and/or test performance?

Findings from these analyses have the potential to inform practitioners with strategies to improve the validity of score-based inferences made from low-stakes educational assessments by improving students' test-taking effort.

\section{Method $^{3}$}

\section{Search Strategy}

Four search strategies were employed: (a) a reference database search; (b) internet browsing; (c) expert consultation; (d) citation searches (both backward and forward). This literature search was completed by March 13, 2019. Specifically, the first strategy employed was a reference database search conducted on February 22, 2019. This approach consisted of selecting six databases in EBSCOhost: (a) Academic Search Premier, (b) PsycINFO, (c) PsycARTICLES, (d) ERIC, (e) CINAHL Complete, and (f) Business Source Complete. The search terms entered into these databases were "test taking" and "motivation" with the Boolean phrase "and." Studies were limited to those published in the English language ${ }^{4}$; however, no other initial restrictions were implemented. The database search was supplemented with internet browsing via Google Scholar in an effort to access a substantial body of articles not published in peer-

\footnotetext{
${ }^{3}$ At the request of the editor and reviewers, the manuscript had to be shortened from its original version to meet the page length requirements for publication in Applied Measurement in Education. To partially accomplish this, the method section was substantially reduced, which resulted in cutting out many details around the search strategy, variable coding, and analyses conducted. For interested readers, I have included a much more thorough method section in Appendix A of the supplementary file.

${ }^{4}$ This led to the exclusion of 16 studies published in German (4), Portuguese (3), Spanish (3), Dutch/Flemish (2), French (1), Hungarian (1), Japanese (1), and Lithuanian (1). It is unclear how many of these studies would have been pertinent to the current meta-analysis.
} 
reviewed journals (grey literature). The same key terms used in the database search were employed. This search was conducted on February 28, 2019. In addition, usable studies were searched for by having informal conversations with or writing emails to a diverse set of colleagues that are known to conduct research in the field of test-taking motivation, such as Steve Wise (Northwest Evaluation Association, USA), Sara Finney (James Madison University, USA), Hannah Eklöf (Umeå University, Sweden), and Christiane Penk (German Institute for International Educational Research [DIPF], Germany). All communication and article retrieval was completed by March 11, 2019. Finally, two citation searches were conducted for any articles meeting the eligibility criteria (described in the next subsection) for the three strategies described above: (a) backward citation searching (i.e., examining the reference list of every included study) utilizing the Social Sciences Citation Index, and (b) forward citation searching (i.e., examining papers that have cited the study of interest) employing Google Scholar. This process was repeated until all references had been searched and no new pertinent studies were included. Both citation search strategies were completed by March 13, 2019.

\section{Eligibility Criteria}

To be included in the meta-analysis, each study had to (a) include a sample of students either in K-12 or higher education (undergraduate or graduate programs) settings; (b) explicitly state that one of the four strategies described by Wise and DeMars (2005) was implemented to improve test-taking effort on a group-based low-stakes educational assessment (i.e., the test had to have no consequences for the students); (c) include a control condition that did not deviate from standard testing practice (i.e., group-based administered assessment with test results having no personal consequences and students receiving no incentive for their test performance); (d) present quantitative results necessary for computing an effect size for either one or both of the 
outcome measures of interest, test-taking effort and/or test performance. Studies were excluded if (a) the students sampled were special needs, as that was beyond the focus of this meta-analysis (e.g., Ayllon \& Kelly, 1972); (b) an intervention was implemented to improve test-taking effort across multiple test administration dates (e.g., Sessoms \& Finney, 2015); (c) an intervention was administered to improve performance on an outcome other than test scores (e.g., class and homework assignments [e.g., Benowitz \& Busse, 1970] and educational surveys [e.g., Chien \& Chang, 2010]). The rationale for the second exclusion criterion was that interventions geared toward improving test-taking effort and test performance across multiple test administration dates is not reflective of typical large-scale group-based educational assessments (e.g., PISA), which generally are administered within a single testing date.

\section{Variable Coding}

Based on a thorough review of the literature, the following eight moderating variables were of both theoretical and practical importance: (a) sample average age ${ }^{5}$; (b) percentage of females in sample; (c) experimental design (randomized versus quasi-experimental); (d) participant recruitment strategy (mandated versus other [volunteering or incentivized]); (e) performance measure item type (selected-response only versus constructed response or mixed item types); (f) length of performance measure (i.e., number of performance measure items); (g) publication type (published versus grey literature); (h) intervention type. To ensure coding consistency, inter-rater reliability was assessed between the author and a research assistant on $20 \%$ of the studies included in the meta-analysis (9 studies in total). Cohen's kappa ( $)$ was used to assess the qualitative agreement (accounting for chance agreement) in ratings across all

\footnotetext{
${ }^{5}$ If not given, the mean age was imputed based on the typical age of students within that grade-level.
} 
dependent variables. A $\kappa$ value of .97 was obtained, suggesting adequate inter-rater agreement (Landis \& Koch, 1977).

\section{Statistical Methods}

The sections that follow describe the procedures for (a) calculating effect sizes; (b) evaluating publication bias; (c) identifying outliers; (d) estimating average effect sizes and effect size heterogeneity; (e) performing moderator analyses.

Calculating effect sizes. Upon coding the means and standard deviations of the treatment conditions for each study, standardized mean difference effect sizes were first computed based on Cohen's $d$ formula and converted to Hedges' $g$ to account for potential overestimation of effect sizes with small samples. These calculations were completed in the $R$ package compute.es (Del Re, 2013).

Publication bias. One criticism of the meta-analytic approach is that results may largely be biased due to a failure to include both published and unpublished literature (Greenhouse \& Iyengar, 2009). Although a concerted effort was made in the search strategies to seek out grey literature, it was important to investigate potential publication bias in this study, which was evaluated by the funnel plot procedure and Duval and Tweedie's (2000) trim-and-fill method using the $L_{0}$ estimator.

Identifying outliers and adjusting effect size estimates. Before conducting moderator analyses, the effect size distribution of each dependent variable was evaluated for outliers via scatterplots. For the dependent variable of interest, any effect size estimate that was greater than three $S D$ (based on the absolute value) from the median effect size across all studies was defined as an outlier. Any effect size identified as an outlier was recoded as a more conservative estimate equal to three $S D$ from the median. A sensitivity analysis was then conducted to evaluate the 
impact of the identified outliers on the estimation of the mean effect sizes for each dependent variable. If any inflation or deflation of the mean effect size under study was observed, the adjusted effect size estimates were used for all subsequent analyses.

Calculating average effect sizes and evaluating effect size heterogeneity. To avoid artificially reducing variance estimates and inflating Type I error due to effect size dependencies (i.e., multiple effect sizes are produced by comparing various treatment conditions to a single condition; Borenstein, Hedges, Higgins, \& Rothstein, 2009), the robust variance estimation (RVE) procedure developed by Hedges, Tipton, and Johnson (2010) was employed using the R package robumeta (Fisher, Tipton, \& Hou, 2016) ${ }^{6}$.

To calculate the average effect of the outcome under study across all interventions, as well as to evaluate the heterogeneity of effect size estimates, a random-effects intercept-only model was fit separately for each dependent variable. ${ }^{7}$ Multivariate meta-regression was not utilized, as the extensiveness of missing data was too great to estimate the correlation between dependent variables. The heterogeneity of effect size estimates was evaluated via the $I^{2}$ statistic proposed by Higgins and Thompson (2002). $I^{2}$ provides a practical interpretation of heterogeneity in which $I^{2}<50 \%$ is representative of small heterogeneity, $50 \% \leq I^{2}<75 \%$ is representative of medium heterogeneity, and large heterogeneity is represented by an $I^{2} \geq 75 \%$ (Higgins \& Thompson, 2002). For each outcome evaluated, a moderator analysis was conducted if there was evidence of at least medium heterogeneity.

\footnotetext{
${ }^{6} \mathrm{~A}$ value must be specified for the correlation between the dependent effect sizes within the robumeta package to estimate the meta-regression model. As noted by Fisher and Tipton (n.d.), the meta-regression estimates are relatively insensitive to changes in the specified correlation, which is what we found when conducting a sensitivity analysis in which multiple values were specified (ranging from .70 to .95). For the analyses within this study, the correlation was set to .80 .

${ }^{7}$ Effect sizes were averaged for any study employing multiple proxies of test-taking effort on the same independent sample (this only occurred for two studies).
} 
A prospective power analysis was conducted to estimate the number of effect sizes needed to yield an average effect size of 0.10 and 0.25 (What Works Clearinghouse criteria for a substantial effect) with $80 \%$ power assuming an average sample size of 150 participants, moderate heterogeneity, and a two-tailed alpha level of .05. Based on these assumptions, this analysis demonstrated that for average effect sizes of 0.10 and 0.25 , a total of 42 and 7 effect sizes is needed to attain $80 \%$ power, respectively.

Moderator analysis. To examine the impact of moderator variables on effect size estimates, the following random-effects meta-regression model was tested:

$\hat{y}=b_{0}+b_{1}($ age $)+b_{2}($ gender $)+b_{3}($ experimental design $)+$ $b_{4}($ recruitment strategy $)+b_{5}($ item type $)+b_{6}($ test content $)+b_{7}($ publication type $)+$ $b_{8}($ test relevance $)+b_{9}($ assessment design $)+b_{10}($ incentives $)+e$,

where $\hat{y}$ was equal to either one of the two dependent variables (test-taking effort or test performance), $b_{0}$ was equal to the average effect size for the dependent variable of interest after controlling for all included variables (not of substantive interest), age was dichotomously coded as K-12 (age $\leq 18)$ versus higher education (age $>18$; reference is $\leq 18$ ), gender was a z-score of the average percentage of female participants across all studies, experimental design was dichotomously coded as experimental versus quasi-experimental (reference group), recruitment strategy was dichotomously coded as mandatory versus incentivized participation or volunteering (reference group), item type was coded dichotomously as selectedresponse versus constructed-response or mixed item formats (reference group), test content was coded as non-STEM versus STEM or mixed (reference), publication type was dichotomously coded as peer-reviewed article versus grey literature (reference), $b_{8}$ through $b_{10}$ were the dummy-coded variables for the test relevance, assessment design, and incentives 
intervention types when treating the feedback condition as the reference group, and $e$ was the residual term.

As mentioned previously, two concerns associated with this analysis were missing data and moderator variability. To address the former issue, any variable with $25 \%$ or more missing data was dropped from the analysis. This was done to mitigate the potential biasing effect that excessive use of data imputation procedures can have (e.g., inaccurate standard error estimation), particularly as the assumptions underlying these procedures (e.g., data missing at random) cannot be tested, and thus, may be untenable (Piggot, 2009). In regards to moderator variability, a major concern is finding a nonstatistically significant association between an outcome and moderator that may be due to a lack of variability. To mitigate misinterpretations of moderator associations, a variable was removed if one level of a categorical variable possessed less than $15 \%$ of the total number of effect sizes or if approximately $70 \%$ of the sample possessed a moderator value that was within one standard deviation of the mean. After controlling for moderator variables, an $F$ statistic was calculated to test the equality of estimates for the intervention type effect sizes using a sandwich estimator for the variance-covariance matrix and a small sample correction for the $p$ value via the clubSandwich $R$ package (Pustejovsky, 2016). If significant at $p<.05$, post-hoc multiple-contrast hypotheses were conducted. To control for Type I error, the Bonferroni procedure (Dunnett, 1955) was employed.

\section{Results}

In total, 5,896 studies were examined based on a database search, internet browsing, consultation, and backward and forward citation searches. Of the 5,896 studies found, 53 were retained following the eligibility criteria outlined earlier in the paper (Figure 1; references for these studies can be found in Appendix B of the supplementary file). These 53 studies produced 
60 effect sizes of test-taking effort and 105 effect sizes of test performance based on 59,096 participants. Table 1 presents the descriptive statistics for sample, methodological, assessment, and publication characteristics of the sampled studies. Trends in publication year suggest a large increase in intervention work within the last decade as $57 \%$ of included studies (30 out of 53) were published since 2010 . In contrast, before the year 2000, only 12 (23\%) studies had been conducted. Furthermore, in regards to sample nationality, 10 out of the 53 studies were conducted outside of the United States with the following countries represented in the sampled literature: Australia, Botswana, Germany, Korea, Malaysia, Nigeria, Sweden, and Turkey.

\section{Publication Bias}

Of the 53 studies included in the meta-analysis, 33 were published in peer-reviewed journals $(62 \%)$, while the remaining 20 were considered grey literature $(38 \%)$. In regards to the latter publication type, manuscripts were conference papers (9 studies), research reports (5 studies), dissertations (5 studies), and works in progress (1 study). These manuscripts were obtained via internet browsing (6 studies), expert consultation (5 studies), backward citation (4 studies), forward citation (3 studies), and database searching (2 studies). No significant associations of academic authorship (authors possessing academic affiliation versus nonacademic affiliation; $r_{\varphi}[51]=.03, p=1.00$ ) or grant funding (grant funded versus not funded; $\left.r_{\varphi}[51]=.05, p=1.00\right)$ by publication type were observed. Furthermore, the distribution of publication year between published $(\min =1972, \max =2019$, median $=2012)$ and grey $(\min =$ $1974, \max =2018$, median $=2010)$ literature was similar when comparing studies that fell into two categories of dates (pre-2010s and 2010s; $\chi^{2}[2,51]=0.88, p=.64$ ). Evaluation of publication bias via the funnel plot demonstrated that effect size estimates were scattered symmetrically across the median effect size across all studies for both the test-taking effort and 
test performance outcomes, suggesting no presence of publication bias (see Appendix C of the supplementary file). This finding was echoed when applying the trim-and-fill method as the estimated number of missing studies on the left side of the distribution was approximately 0 for both test-taking effort $(0.06, S E=0.03)$ and test performance $(0.10, S E=0.02)$. Based on descriptive analyses as well as the funnel plot and trim-and-fill procedures, publication bias did not appear to be present in the sample of studies.

\section{Identifying Outliers and Adjusting Effect Size Estimates}

To ensure that outliers did not impact the validity and robustness of the conclusions drawn from this meta-analysis, scatterplots of effect sizes for both the test-taking effort and test performance outcome variables were created. One effect size estimate was found to be greater than three $S D$ from the median effect size across all studies for test-taking effort, while this was the case for two test performance effect sizes. These estimates were considered outliers and, as a result, were restricted to be equal to the value associated with three standard deviations from the median respectively for both outcomes. A sensitivity analysis was then conducted to evaluate the impact of adjusting the effect size estimates when compared to making no adjustments. Results demonstrated that the average effect size for test-taking effort decreased by less than one onehundredth of a decimal point (.005 SD) when adjusting the effect size estimates for outliers. Furthermore, the $I^{2}$ value or the amount of heterogeneity in effect size estimates across studies was found to decrease by $0.30 \%$. Larger findings were obtained for the test performance outcome in that adjusting the effect size estimates led to a decrease of the mean effect size across studies by $0.013 S D$, while the degree of heterogeneity in effect sizes decreased by $3.86 \%$. Taken together, the sensitivity analysis demonstrated that the outliers had a relatively minimal impact on inflating both average effect size estimates as well as estimates of heterogeneity across both 
outcome variables. Though a minimal impact, to improve the validity of the inferences made from this meta-analysis, the adjusted effect sizes were used for all remaining analyses.

\section{Average Effect Sizes and Heterogeneity}

The overall mean impact of interventions on test-taking effort was an improvement of $0.13 S D(p<.01 ; 95 \%$ CI [0.04, 0.22]), which was based on 60 effect sizes obtained from 28 distinct studies (Figure 3). A large degree of heterogeneity was observed across these effect sizes $\left(I^{2}=89.63 \%\right)$, suggesting the need for moderator analyses to explain the variance. In regards to test performance, the interventions were found to have an overall impact of $0.13 S D(p<.01$; 95\% CI [0.06, 0.19]) based on sampling 49 studies that produced 105 effect sizes (Figure 4). In regards to the heterogeneity of effect sizes, the $I^{2}$ was equal to $83.11 \%$, indicating large heterogeneity and prompting further investigation of effect size divergence in the literature. Although the covariance between test-taking effort and test performance was not modeled due to a large amount of missing data (i.e., only 15 of 53 studies reported the correlation between the two dependent variables), the inverse variance weighted mean correlation for 32 reported effect sizes was equal to $0.34(95 \% \mathrm{CI}[0.31,0.38])$, suggesting a positive relationship between the two dependent variables.

\section{Moderator Analyses}

Table 2 provides the results of the moderator analyses. Below, differences in effect sizes attributable to moderators by sample, methodological, assessment, publication, and intervention characteristics are described.

Sample characteristics. To study whether sample characteristics significantly moderated effect size estimates, both the standardized proportion of females in a study sample and participant age (comparing students $>18$ and those $\leq 18$ years old) were evaluated. Descriptive 
results showed that of the 83 samples reporting gender demographics, females on average comprised $57 \%(S D=9 \% ; \min =44 \% ; \max =83 \%)$ of participants, and $81 \%$ of samples possessed a proportion of female participants that was within one standard deviation of the mean across all studies. Although the initial intent was to examine differences based on gender demographics, descriptive results demonstrated a lack of variability for this variable in the sampled literature. Thus, to mitigate misinterpretations concerning the role of gender on the studied outcomes, this variable was dropped from the analysis.

Across 91 independent samples, the average age of participants was 16.75 years $(S D=$ 3.87) with $49 \%$ of samples coming from higher education settings. An examination of age as a moderator demonstrated that after controlling for all other variables, the average impact of motivation interventions on test-taking effort was significantly larger for higher education samples when compared to K-12 samples $(0.14 S D ; p<.05)$. Though, the opposite was found when examining test performance. Specifically, the average impact of motivation interventions for higher education samples was significantly lower than K-12 samples by $0.13 S D(p<.05)$.

Methodological characteristics. The role of methodological characteristics as potential moderators was investigated by evaluating participant recruitment strategies (required versus voluntary or incentivized participation) and experimental designs (experimental versus quasiexperimental designs). Of the 114 samples reporting recruitment strategies, only $19 \%$ obtained participants via incentives and volunteering. Incentives included extra credit, gift cards, or cash payments varying from $\$ 0.50$ to $\$ 50$ for meeting a performance criterion at either the item or assessment level, respectively. In regards to experimental designs, nearly $67 \%$ of 117 samples were randomized at the individual-level into experimental conditions. Model results indicated that, on average, studies employing random assignment did not possess significantly different 
mean effect sizes for test-taking effort $(0.08 S D ; p=.15)$ nor test performance $(-0.03 S D ; p=$ .40) when compared to quasi-experimental designs. Studies that required study participation possessed an average test-taking effort effect size that was $0.34 S D(p<.01,95 \%$ CI [-0.54, 0.14]) lower than studies that either incentivized or relied on volunteering for participant recruitment; however, no significant differences were observed for test performance (-.03 $S D ; p$ $=.37)$.

Assessment characteristics. Across studies and dependent variables, approximately $73 \%$ of assessments were comprised solely of selected-response options, $10 \%$ were made up of only open-ended items, and 17\% possessed mixed item types; however, for the studies that investigated test-taking effort as a dependent variable, less than 5\% of effect sizes included an outcome measure with non-selected response items. Consequently, due to the lack of variability, this independent variable was dropped as a moderator of test-taking effort. In contrast, $27 \%$ of test performance effect sizes included non-selected items, and as a result, it was included as a moderator. Results demonstrated that students who were administered an assessment of only selected-response items had an average effect size of test performance that was not statistically different than students administered an assessment of constructed-response or mixed-item types $(0.17 S D ; p=.06)$. In regard to test content, only three of the 49 reported test-taking effort effect sizes reported assessing students on non-STEM content. As a consequence of minimal variability, this variable was dropped from the test-taking effort moderator analysis. Though, for the test performance dependent variable, the test content assessed was much more variable. Specifically, of the 105 effect sizes reported, 27\% assessed a non-STEM content area, while the remaining 73\% assessed STEM or mixed test content. After controlling for all other variables in the model, results showed a non-significant difference between test content areas on test 
performance $(0.02 S D ; p=.37)$, rejecting the hypothesis that motivation interventions better improve STEM or mixed test content.

Publication type. Publication type (journal article versus grey literature) was evaluated as a potential moderating variable of test-taking effort and test performance. In terms of the former dependent variable, after controlling for all other moderators, a significant difference was observed between published $(n=30)$ and grey literature $(n=30)$. Specifically, the average effect size for published studies was $0.13 S D(p<.05 ; 95 \%$ CI $[0.00,0.26])$ higher than that found for grey literature. For the test performance dependent variable, the number of effect sizes included by publication type was similar with published and grey literature studies producing 61 and 44 effect sizes, respectively. Unlike the differences observed in test-taking effort, there were no significant differences in mean effect sizes across publication types $(0.08 S D ; p=.11)$.

Intervention type. Before describing the average effect sizes for each outcome by intervention type, it is important to first review the approaches that researchers have employed to improve test-taking effort and test performance in low-stakes contexts. Across dependent variables, the most popular approach employed (based on the number of unique studies employing each intervention) was modifying assessment designs (29 independent samples). The most common modifications were to make the assessment adaptive (45\%) and improve the test administration process (e.g., using online proctors, training live proctors to be more aware of test-taking effort issues, adaptively providing warning signs to students engaging in rapid guessing or providing praise to students not engaged in rapid guessing, and specifying the optimum item-level response time; 34\%). The remaining studies tested a number of unique approaches, such as comparing different modes of presentation (computer-based and tablet versus paper-based assessments; 7\%), comparing short and long forms of an assessment (3.5\%), 
priming students' effort via a game given before test administration (3.5\%), incorporating gamification principles into assessment design (3.5\%), and adding pictures to items (3.5\%).

Nearly equally represented in the sample of studies was the investigation of promising feedback and increasing test relevance. Of the 24 samples administered the feedback intervention, $54 \%$ received general summative feedback, while the remaining $46 \%$ of samples received criterion-referenced (17\%), item-level (12.5\%), norm-referenced $(12.5 \%)$, and diagnostic (4\%) feedback. In terms of improving test relevance, 23 total samples were tested in which students were told that results would be used to (a) evaluate instruction (22\%); (b) compare students' proficiencies (17\%); (c) make institutional improvements (13\%); (d) understand student skills (9\%); (e) some combination of the approaches noted above (17\%). In addition to the aforementioned approaches to improving test relevance, students were told that they would receive a feeling of personal accomplishment by trying their best (17\%) and that assessment results would be released to faculty and potential employers (4\%).

In regard to external incentives, of the 22 samples tested, $93 \%$ were performancecontingent and $68 \%$ administered a monetary incentive. Of the samples awarded a monetary incentive, seven received financial incentives for total score performance ranging from $\$ 1$ to $\$ 20$ for either improving their score above an a priori criterion or meeting a specified proficiency level. The remaining seven samples received an item-level financial incentive in which each correct item response was compensated with as little as five cents and as much as $\$ 15$. In addition to monetary incentives, researchers also rewarded students with academic awards (e.g., trophies or certificates; $9 \%$ of samples), raffles (14\% of samples), and prizes (e.g., candy, tshirts; $9 \%$ of samples). Although nearly all studies employed one of the four intervention types listed above, there were a minority of studies that combined two of the approaches (e.g., 
increasing test relevance and modifying the assessment design $[\mathrm{n}=6]$, modifying the assessment design and providing external incentives $[\mathrm{n}=1]$, modifying the assessment design and promising feedback $[n=2])$.

Table 3 shows that the unadjusted means by intervention type for test-taking effort were largest in order for the external incentives ${ }^{8}(0.36 S D)$, test relevance $(0.21 S D)$, assessment design (0.13 SD), and promising feedback (-0.01 SD) interventions. After controlling for the moderators noted above, an omnibus test of equality showed that the coefficients for the three modeled interventions (promising feedback, assessment design, and external incentives) were significantly different $(F[2,9]=7.72, p<.01)$. Closer examination of the regression coefficients demonstrated that both the feedback $(\beta=-0.00, p=.97)$ and assessment design $(\beta=0.16, p=$ .16) intervention effects were not statistically different from that of the test relevance intervention. However, the external incentive intervention was found to produce larger improvements in test-taking effort when compared to test relevance by an average of $0.37 S D(p$ $<.05 ; 95 \%$ CI: 0.05, 0.69). Post-hoc multiple-contrast tests showed that the coefficients of the promising feedback $(F[1,7]=18.2, p<.01)$ and assessment design $(F[1,12]=11.8, p<.01)$ interventions were significantly smaller when compared to that of the external incentives intervention at a Bonferroni-adjusted alpha-level of .012. Taken together, these results indicate that the external incentives intervention was associated with the largest improvements in testtaking effort contrasted with all other interventions when controlling for methodological and substantive moderators.

\footnotetext{
${ }^{8}$ Although the sample sizes were too small to conduct a statistical test, nonmonetary incentives $(\mathrm{n}=3)$ were found to possess an average unadjusted mean effect size that was $0.43 S D$ larger than monetary incentives $(\mathrm{n}=6)$.
} 
In regard to the test performance dependent variable, the unadjusted means were largest in order for the test relevance $(0.27 S D)$, external incentives ${ }^{9}(0.21 S D)$, assessment design $(0.06$ $S D)$, and promising feedback $(0.05 S D)$ interventions. Model results demonstrated that, after controlling for moderators, the effects of the feedback and assessment design interventions were associated with significantly lower performance improvements of $0.22 S D[p<.05 ; 95 \% \mathrm{CI}$ : $0.42,-0.02]$ and $0.23 S D[p<.05 ; 95 \% \mathrm{CI}:-0.45,-0.01]$ when compared to the test relevance intervention, respectively. Furthermore, no significant differences in intervention effects were found when comparing the external incentives and test relevance interventions $(-0.13 S D ; p=$ $.31 ; 95 \%$ CI: $-0.39,0.13)$. Overall, these results suggest that both the external incentives and test relevance interventions were the most effective in improving test performance.

\section{Discussion}

The objective of this meta-analysis was to examine the effectiveness of interventions developed to improve test-taking effort in low-stakes, group-based educational assessments. Overall, across all 53 studies analyzed, the average treatment effect of test-taking effort and test performance was an improvement of $0.13 S D$ each. Across both dependent variables, sample age was found to be a significant moderator, although the relationship was inverse for test-taking effort and test performance. Specifically, motivation interventions were found to have a significantly larger impact on test-taking effort for higher education samples $(0.14 S D)$, but a significantly lower impact on test performance when compared to K-12 samples (-0.13 SD). One reason for this may be that the majority of studies relied on self-report measures for test-taking effort (discussed further below), which are susceptible to social desirable responding (i.e., responding to questions in a way that will be viewed favorably by others). Prior research has

\footnotetext{
${ }^{9}$ It should be noted that for the external incentives intervention, no significant difference in unadjusted means was found between monetary $(\mathrm{n}=13)$ and non-monetary incentives $(\mathrm{n}=8 ; p=.41)$.
} 
shown that social desirable responding is greater in survey research for older samples, which may be why the improvement of test-taking effort was not translated to test performance for higher education samples (Steenkamp, de Jong, \& Baumgartner, 2010). Although test performance effect sizes were found to be robust to all other moderator variables analyzed, testtaking effort was observed to be moderated by participant recruitment strategy and publication type in addition to sample age. Specifically, studies that recruited students by incentivizing or relying on volunteering for participation on average had effect sizes that were $0.34 S D$ higher than studies that mandated student participation. In addition, studies that were published in peerreviewed journals possessed average effect sizes that were $0.13 S D$ higher than those that were not.

After controlling for all moderators, the largest treatment effect on test-taking effort was obtained by the external incentives intervention type. Similarly, this intervention type was also found to have the largest impact along with the test relevance intervention on test performance. Assuming that noneffortful responding is unrelated to ability, the unadjusted mean improvement in test performance observed for these interventions translates to an average reduction of approximately $12.5 \%$ of noneffortful responses in a data matrix for a moderately difficult assessment (Rios et al., 2017). One hypothesis for the effectiveness of these interventions over modifying assessment design and promising feedback is that they explicitly stipulate to the test takers that maximal effort is desired with the former communicating the importance of the assessment results to stakeholders, while the latter targets the personal benefits to individual test takers for performing well. Although one can make the argument that the same would be the case for promising feedback, this would require that the test taker is interested in getting feedback in the content area being assessed. If not, then a test taker may see little value in the assessment. Of 
all the intervention types examined, many of the modifying assessment design interventions (e.g., making the assessment adaptive, altering presentation modes) made the least effort to communicate the importance of putting forth maximal effort to students, and as such, had little impact on the dependent variables examined.

\section{Limitations}

A number of limitations associated with this study should be noted. First, although a concerted effort was made to include a diverse set of literature search strategies, some pertinent papers may have been missed based on only including English language papers and failing to consult professional research organization listservs. Second, the variables that could be included in the moderator analyses were limited due to both sample size restrictions and a lack of heterogeneity in the literature. Thus, the analyses focused primarily on sample (age and gender), methodological (research design and participant recruitment strategy), assessment (item type and test content), and publication (journal versus grey literature) characteristics; however, there were a few variables that were not examined, which could be of importance for future research. As an example, future research could include variables related to intervention features besides type, such as when the intervention was administered (i.e., before or during testing), the explicitness of the intervention (i.e., whether students were specifically told that they needed to put forth maximum effort), and intervention adaptability (i.e., an intervention's ability to be employed based on an individual's effort).

Lastly, in conducting the statistical analyses, the covariance of the dependent variables was not controlled for, and thus, separate univariate analyses were conducted, which may have resulted in an upward bias in study-level variances, fixed effects, and associated standard errors (Riley, Thompson, \& Abrams, 2008). Ideally, the covariance between test-taking effort and test 
performance would have been modeled, however, only $42 \%$ of studies measured both outcomes, and of those that did, nearly $30 \%$ did not report a correlation. Although, Raudenbush and Bryk (2002) proposed imputing the mean of the covariance for all studies that have reported the relationship between the variables of interest, such a solution was not applicable in this synthesis for two reasons. First, there has been limited prior research summarizing the correlation between test-taking effort and test performance to use as an estimate for imputation. Second, relying on the data with its extensive missingness would have most likely resulted in biasing the model estimates as mean imputation would assume an invariant relationship for various sample demographics (e.g., gender and age), measures of test-taking effort (e.g., surveys and response time information), test content (e.g., cognitive and non-cognitive), and so forth; such an assumption was untenable in this study. Therefore, separate univariate analyses were conducted for each dependent variable and the inverse weighted mean correlation was reported solely for descriptive purposes.

\section{Implications for Future Research}

The aforementioned limitations aside, the findings from this study point to a number of important implications for future research. First, in evaluating the utility of test-taking effort interventions, it is important to evaluate test-taking effort as opposed to relying solely on test performance as an indicator of intervention effectiveness. Although this seems straightforward, of the 53 studies included in the analysis, 25 (47\%) either did not evaluate test-taking effort as a dependent variable or did not report the necessary information that would allow for the calculation of test-taking effort effect sizes. By only focusing on test performance, it is difficult to determine whether an intervention was effective for a number of reasons. For one, the assumption that test-taking effort leads to significantly large improvements in test performance 
may be untenable for low ability students as increased effort does not necessarily make one more able, but allows for a more accurate reflection of one's ability (see Rios et al., 2017). This assertion is supported by descriptive findings in which the average inverse variance weighted correlation between effort and test performance was .34 across 32 effect sizes, suggesting that the majority of test performance variance was accounted for by other factors. A second limitation of relying solely on test performance is that group differences may largely be confounded by ability differences. Such an issue may not have been prevalent for studies employing randomization in assigning participants to experimental and control conditions, but for the 25 studies that did not measure test-taking effort, $24 \%$ employed a quasi-experimental design and did not report examining group equivalence. Consequently, any differences between experimental and control conditions on test performance may have been due to initial ability differences between participants. Clearly, improved rigor is required along with a focus on measuring both test-taking effort and test performance as dependent variables in evaluating the utility of effort interventions.

In regard to measuring test-taking effort, a strong reliance on using self-report measures was found (i.e., $68 \%$ of effort effect sizes were based on this proxy) with the majority of studies employing the Student Opinion Scale (SOS) developed by Sundre and Moore (2002). The remaining $32 \%$ of effort effect sizes were predominately based on the use of response time information. It is clear why such an over-reliance on self-report measures in the literature was observed. For one, they require very little resources as they (a) can be obtained at no charge for use in research settings; (b) do not require special computer software as part of the data collection process; (c) can be used in studies where the test performance measure is administered either via paper-and-pencil or computer; (d) can measure multiple components of test-taking 
motivation (e.g., interest, value, and effort), whereas other proxies, such as response time information, may only be acceptable proxies of test-taking effort. Although self-report measures have their advantages, they also present two major limitations: (a) they are susceptible to response bias (Wise \& DeMars, 2006) and (b) they assess test-taking effort at the global-level, which may be problematic as previous research has shown that test-takers' effort may change throughout different phases of test administration (Wise \& Kingsbury, 2016). As a result, it is unclear whether self-reported test-taking effort was reflective of students' actual effort on the assessment of interest. If not, the use of self-report measures in the analysis may have biased the inferences made regarding the effectiveness of intervention effects on test-taking effort. Consequently, it is unknown whether the results would still hold had researchers employed more unobtrusive proxies of effort, such as collecting response time information, as opposed to selfreport measures. Therefore, future research should employ multiple proxies to verify the effectiveness of a test-taking effort intervention. Furthermore, it is recommended that researchers employing self-report measures should include a scale that evaluates the presence of socially desirable responding prior to interpreting the impact of motivation interventions on test-taking effort.

Lastly, it was found that nearly all researchers focused their level of analysis at the total group level without differentiating among subgroups (e.g., gender, ability). However, previous research has shown that within certain contexts test-taking effort may differ by (a) age (e.g., Liu et al., 2012; Rios \& Liu, 2017; Thelk et al., 2009); (b) ethnicity (Chan, Schmitt, DeShon, Clause, \& Delbridge, 1997; DeMars, 2000); (c) nationality (e.g., Debeer, et al., 2014; Goldhammer et al., 2016); (d) academic ability (Rios et al., 2017); (e) personality traits (e.g., conscientiousness; Freund \& Holling, 2011). Consequently, ignoring individual differences in factors that impact 
test-taking effort may lead to an inaccurate perception of intervention effectiveness. As a result, there is a need to reframe the question of an intervention's utility from "Does it work?" to "For whom does it work?" In doing so, we may better understand how to develop interventions that are tailored to the student population of interest as there may be no one-size-fits-all solution.

\section{Recommendations for Practitioners}

The results from the meta-analysis are illuminating not only for future research but also for practice. In particular, the findings point to three important recommendations. The first is to be cognizant that how participants are recruited may impact the effectiveness of test-taking effort interventions. That is, by making participation mandatory, interventions may be less impactful than when recruiting students by providing incentives (e.g., money, gift cards, being entered into a raffle, or early course registration) or relying on volunteering. According to Expectancy-Value Theory, such a result may suggest that the latter recruitment strategies provide students with higher subjective interest in the assessment that is minimally required for an intervention to be impactful (Steedle, Zahner, \& Kugelmass, 2014). Therefore, to obtain a sample that may be more open to engaging with a test-taking effort intervention due to increased assessment value, testing programs should (a) create student recognition of the assessment process by effectively communicating the purpose and importance of the assessment to students while recruiting (for recommendations, see Zilberberg, Brown, Harmes, \& Anderson, 2009); (b) increase participation by consulting with students about the types of non-financial incentives (e.g., early course registration access, extra recess time) that would be both of greatest interest to students and feasible from a resource standpoint for the testing program (see Steedle et al., 2014); (c) ensure that the obtained sample is representative of the student population (Mägi et al., 2013). 
The second recommendation associated with the study findings is that providing students with performance-contingent external incentives may improve both test-taking effort and test performance on low-stakes educational assessments. One limitation associated with this intervention type is that it may be unfeasible for practitioners to provide students with monetary incentives due to limited financial resources; however, no significant differences in unadjusted means were found for either dependent variable when comparing monetary and nonmonetary incentives. From a theoretical standpoint, Frey (2007) has noted that this latter incentive type may be effective for two reasons. First, it shows students the types of behaviors that are desired and valued (i.e., putting forth maximum test-taking effort), which allows them to signal their ability to display these behaviors. Second, although an extrinsic incentive, it may allow students to simultaneously maintain their task-specific intrinsic motivation (see Cameron \& Pierce, 1994). The reason being that performance-contingent incentives provide information regarding proficiency, and thus, promote autonomy and competence, which are two psychological needs underlying intrinsic motivation (e.g., Deci \& Ryan, 1980). Although there is clearly a need for more research on the role of nonmonetary incentives' impact on students' test-taking behavior, initial results suggest that testing programs may be able to improve effort and performance in a cost-effective manner. Additionally, though far less effective in improving test-taking effort when compared to external incentives, increasing test relevance was equally as effective in improving test performance. From a theoretical standpoint, this result suggests that appealing to test-takers' perceptions of importance may improve test performance, though not test-taking effort. Such a finding suggests the need for more research on this intervention type, particularly for studies that use non-mandatory approaches to participant recruitment. Furthermore, limited evidence suggests that combining test relevance and external incentives interventions may be 
particularly successful in improving test performance $(d=0.43$; Patrick, Kpangban, Chibueze, 2007); though more research is also needed in this area.

The final recommendation for practitioners is to avoid solely relying on the use of testtaking effort interventions to improve the validity of inferences made from low-stakes assessments. That is, it is recommended that practitioners employ a two-stage approach to address potential low test-taking effort. This would require administering an intervention along with utilizing post-hoc methods to identify and filter careless responses as interventions may not be effective for all students across the entire assessment. Extensive research has been conducted comparing different proxies of test-taking effort (e.g., Rios et al., 2014; Swerdzewski et al., 2011) and filtering methods (e.g., Rios et al., 2017). Each procedure provides its own practical and theoretical advantages and disadvantages, which practitioners must weigh; however, if used correctly, this post-hoc approach coupled with employing a test-taking effort intervention may be an effective strategy. Overall, this recommendation along with the others is expected to assist practitioners with managing low test-taking effort to improve the validity of test score interpretations from low-stakes group-based educational assessments. Clearly, more investigations on this topic are needed, however, it is the hope that this study has laid the foundation for future research. 


\section{References}

American Educational Research Association (2000). Position statement of the American Educational Research Association concerning high-stakes testing in PreK-12 education. Educational Researcher, 29, 24-25.

American Educational Research Association, American Psychological Association, \& National Council on Measurement in Education (2014). Standards for educational and psychological testing (6 $6^{\text {th }}$ ed.). Washington DC: American Educational Research Association.

Attali, Y., \& Arieli-Attali, M. (2015). Gamification in assessment: Do points affect test performance? Computers \& Education, 83, 57-63.

Ayllon, T., \& Kelly, K. (1972). Effects of reinforcement on standardized test performance. Journal of Applied Behavior Analysis, 5, 477-484.

Baker, E. L., Barton, P. E., Darling-Hammond, L., Haertel, E., Ladd, H. F., Linn, R. L., ...Shepard, L. A. (2010). Problems with the use of student test scores to evaluate teachers [Briefing paper \#278]. Washington, D. C.: Economic Policy Institute.

Bandura, A. (1977). Self-efficacy: toward a unifying theory of behavioral change. Psychological Review, 84, 191-215.

Bandura, A. (1993). Perceived self-efficacy in cognitive development and functioning. Educational Psychologist, 28, 117-148.

Becker, B. J. (1988). Synthesizing standardized mean-change measures. British Journal of Mathematical and Statistical Psychology, 41, 257-278.

Bennett, R. E. (2016). Opt out: An examination of Issues (ETS RR-16-13). Princeton, NJ: Educational Testing Service. 
Benowitz, M. L., \& Busse, T. V. (1970). Material incentives and the learning of spelling words in a typical school situation. Journal of Educational Psychology, 61, 24-26.

Bornstein, M., Hedges, L. V., Higgins, J., \& Rothstein, H. R. (2009). Introduction to metaanalysis. John Wiley \& Sons: Chichester, UK.

Burke, P. (1991). You can lead adolescents to a test but you can't make them try. Washington, D.C.: Office of Technology Assessment.

Butler, J. C. (2008). Interest and effort in large-scale assessment: The influence of student motivational variables on the validity of reading achievement outcomes (Unpublished doctoral dissertation). University of Melbourne, Melbourne, Australia.

Cameron, J., \& Pierce, W. D. (1994). Reinforcement, reward, and intrinsic motivation: A metaanalysis. Review of Educational Research, 64, 363-423.

Chan, D., Schmitt, N., DeShon, R. P., Clause, C. S., \& Delbridge, K. (1997). Reactions to cognitive ability tests: The relationships between race, test performance, face validity perceptions, and test-taking motivation. Journal of Applied Psychology, 82, 300-310.

Cheung, A. C., \& Slavin, R. E. (2016). How methodological features affect effect sizes in education. Educational Researcher, 45, 283-292.

Chien, Y. T., \& Chang, C., Y. (2010). Exploring the feasibility of an online contextualized animation-based questionnaire for educational survey. British Journal of Educational Technology, 41, E104-E109.

Coe, R. (1998). Can feedback improve teaching? A review of the social science literature with a view to identifying the conditions under which giving feedback to teachers will result in improved performance. Research Papers in Education, 13, 43-66.

Cole, J. S., Bergin, D. A., \& Whittaker, T. A. (2008). Predicting student achievement for low 
stakes tests with effort and task value. Contemporary Educational Psychology, 33, 609624.

Debeer, D., Buchholz, J., Hartig, J., \& Janssen, R. (2014). Student, school, and country differences in sustained test-taking effort in the 2009 PISA reading assessment. Journal of Educational and Behavioral Statistics, 39, 502-523.

Deci, E. L., \& Ryan, R. M. (1980). The empirical exploration of intrinsic motivational processes. Advances in Experimental Social Psychology, 13, 39-80.

Del Re, A. C. (2013). Compute.es: Compute effect sizes. R package version 0.2-2. Retrieved from https://cran.r-project.org/web/packages/compute.es/compute.es.pdf

DeMars, C. E. (2000). Test stakes and item format interactions. Applied Measurement in Education, 13, 55-77.

DeMars, C. E., Bashkov, B. M., \& Socha, A. B. (2013). The role of gender in test-taking motivation under low-stakes conditions. Research \& Practice in Assessment, 8, 69-82.

Duckworth, A. L., Quinn, P. D., Lynam, D. R., Loeber, R., \& Stouthamer-Loeber, M. (2011). Role of test motivation in intelligence testing. Proceedings of the National Academy of Sciences of the United States of America, 108, 7716-7720.

Dunnett, C. W. (1955). A multiple comparisons procedure for comparing several treatments with a control. Journal of the American Statistical Association, 50, 1096-1121.

Duval, S., \& Tweedie, R. (2000). Trim and fill: a simple funnel-plot-based method of testing and adjusting for publication bias in meta-analysis. Biometrics, 56, 455-463.

Eccles, J. S., \& Wigfield, A. (2002). Motivational beliefs, values, and goals. Annual Review of Psychology, 53, 109-132.

Eisenkopf, G. (2011). Paying for better test scores. Education Economics, 19, 329-339. 
Eklöf, H. (2010). Skill and will: Test-taking motivation and assessment quality. Assessment in Education: Principles, Policy \& Practice, 17, 345-356.

Fisher, Z., \& Tipton, E. (n.d.). Robumeta: An R-package for robust variance estimation in metaanalysis. Retrieved from http://blogs.cuit.columbia.edu/let2119/files/2013/03/Fisher-andTipton-.pdf

Fisher, Z., Tipton, E., \& Hou, Z. (2016). Robumeta: Robust variance meta-regression. R package version 1.8. Retrieved from https://cran.r-project.org/web/packages/robumeta/robumeta .$p d f$

Freund, P. A., \& Holling, H. (2011). Who wants to take an intelligence test? Personality and achievement motivation in the context of ability testing. Personality and Individual Differences, 50, 723-728.

Frey, B. (2007). Awards as compensation. European Management Review, 4, 6-14.

Goldhammer, F., Martens, T., Christoph, G., \& Lüdtke, O. (2016). Test-taking engagement in PIAAC (OECD Education Working Papers, No. 133). Paris, France: OECD Publishing.

Gonzalez, H. B., \& Kuenzi, J. J. (2012). Science, technology, engineering, and mathematics (STEM) education: A primer. Congressional Research Service: Washington, D.C.

Greenhouse, J. B., \& Iyengar, S. (2009). Sensitivity analysis and diagnostics. In H. Cooper, L. V. Hedges, and J. C. Valentine (Eds.), The Handbook of Research Synthesis and MetaAnalysis (2 ${ }^{\text {nd }}$ Ed.; pp. 103-126). New York, NY: Russell Sage Foundation.

Griffin, M. M., Griffin, B. W., Warkentin, R. W., Quinn, G. P., Driscoll, M. P., \& McCown, R. R. (1995, April). The effects of cooperative assessment on goals, perceived ability, selfregulation, and achievement. Paper presented at the Annual Meeting of the American Educational Research Association, San Francisco, CA. 
Haddaway, N. R., Collins, A. M., Coughlin, D., \& Kirk, S. (2015). The role of Google Scholar in evidence reviews and its applicability to grey literature searching. PLos One, 10(9). Retrieved from http://journals.plos.org/plosone/article?id=10.1371/journal.pone.0138237

Hallgreen, K. A. (2012). Computing inter-rater reliability for observational data: An overview and tutorial. Tutorials in Quantitative Methods for Psychology, 8, 23-34.

Harackiewicz, J. M., Manderlink, G., \& Sansone, C. (1984). Rewarding pinball wizardry: Effects of evaluation and cue value on intrinsic interest. Journal of Personality and Social Psychology, 47, 287-300.

Hattie, J., \& Timperley, H. (2007). The power of feedback. Review of Educational Research, 77, $81-112$.

Hawthorne, K. A., Bol, L., Pribesh, S., \& Suh, Y. (2015). Effects of motivational prompts on motivation, effort, and performance on a low-stakes standardized test. Research \& Practice in Assessment, 10, 30-38.

Hedges, L. V., \& Pigott, T. D. (2004). The power of statistical tests for moderators in metaanalysis. Psychological Methods, 9, 426-445.

Hedges, L. V., Tipton, E., \& Johnson, M. C. (2010). Robust variance estimation in metaregression with dependent effect size estimates. Research Synthesis Methods, 1, 39-65.

Hidi, S., \& Harackiewicz, J. M. (2000). Motivating the academically unmotivated: A critical issue for the 21st century. Review of Educational Research, 70, 151-179.

Higgins, J., \& Thompson, S. G. (2002). Quantifying heterogeneity in a meta-analysis. Statistics in Medicine, 21, 1539-1558.

Kirk, R. E. (1995). Experimental design: Procedures for the behavioral sciences. Brooks/Cole Publishing Company: Pacific Grove, CA. 
Kosh, A. (2017, April). Does context personalization of mathematics word problems reduce rapid guessing? Poster presented at the annual meeting of the National Council on Measurement in Education, San Antonio, TX.

Landis, J. R., \& Koch, G. G. (1977). The measurement of observer agreement for categorical data. Biometrics, 33, 159-174.

Lazowski, R. A., \& Hulleman, C. S. (2016). Motivation interventions in education: A metaanalytic review. Review of Educational Research, 86, 602-640.

Lecian, L. V. M. (1985). Effects of coaching on developing cognitive abilities test scores (unpublished doctoral dissertation). Arizona State University, Tempe, AZ.

Mägi, M. L., Adov, L., Must, O., \& Täht, K. (2013). Who is willing to take low-stakes assignments? Trames, 4, 417-432.

Marsh, J. A., Pane, J. F., \& Hamilton, L. S. (2006). Making sense of data-driven decision making in education. Santa Monica, CA: RAND Corporation.

McAuley, L., Pham, B., Tugwell, P., \& Moher, D. (2000). Does the inclusion of grey literature influence estimates of intervention effectiveness reported in meta-analyses? The Lancet, 356, 1228-1231.

Muralidharan, K., \& Sundararaman, V. (2010). The impact of diagnostic feedback to teachers on student learning: Experimental evidence from India. The Economic Journal, 120, F187F203.

Osborne, J. W., \& Blanchard, M. R. (2011). Random responding from participants is a threat to the validity of social science research results. Frontiers in Psychology, 1, 1-7.

Penk, C., \& Schipolowski, S. (2015). Is it all about value? Bringing back the expectancy component to the assessment of test-taking motivation. Learning and Individual 
Differences, 42, 27-35.

Piggot, T. D. (2009). Handling missing data. In H. Cooper, L. V. Hedges, and J. C. Valentine (Eds.), The Handbook of Research Synthesis and Meta-Analysis (2 ${ }^{\text {nd }}$ Ed.; pp. 399-416). New York, NY: Russell Sage Foundation.

Pintrich, P. R., \& Schunk, D. H. (2002). Motivation in education: Theory, research, and applications. Upper Saddle River, NJ: Merrill Prentice Hall.

Pustejovsky, J. (2016). clubSandwich: Cluster-robust (sandwich) variance estimators with smallsample corrections. R package version 0.2.2.

Raudenbush, S. W., \& Bryk, A. S. (2002). Hierarchical linear models: Applications and data analysis methods. Sage: Thousand Oaks, CA.

Riley, R. D., Thompson, J. R., \& Abrams, K. R. (2008). An alternative model for bivariate random-effects meta-analysis when the within-study correlations are unknown. Biostatistics, 9, 172-186.

Rios, J. A., Guo, H., Mao, L., \& Liu, O. L. (2017). Evaluating the impact of careless responses on aggregated scores: To filter unmotivated examinees or not? International Journal of Testing, 17, 74-104.

Rios, J. A., Liu, O. L., \& Bridgeman, B. (2014). Identifying unmotivated examinees on student learning outcomes assessment: A comparison of two approaches. New Directions for Institutional Research, 161, 69-82.

Rosenthal, R., \& Rosnow, R. L. (2008). Essentials of behavioral research: Methods and data analysis ( $3^{\text {rd }}$ ed.). New York, NY: McGraw-Hill.

Rothe, H. F. (1947). Output rates among machine operators: Distributions and their reliability. Journal of Applied Psychology, 31, 484-489. 
Rothstein, H. R., \& Hopewell, S. (2009). Grey literature. In H. Cooper, L. V. Hedges, and J. C. Valentine (Eds.), The Handbook of Research Synthesis and Meta-Analysis (2 ${ }^{\text {nd }}$ Ed.; pp. 103-126). New York, NY: Russell Sage Foundation.

Ryan, R. M., Mims, V., \& Koestner, R. (1983). Relation of reward contingency and interpersonal context to intrinsic motivation: A review and test using cognitive evaluation theory. Journal of Personality and Social Psychology, 45, 736-750.

Sangmeister, J. (2017). Commercial competence: Comparing test results of paper-and-pencil versus computer-based assessments. Empirical Research in Vocational Education and Training, 9(3), 1-19.

Schunk, D. H. (1984, April). Self-efficacy and classroom learning. Paper presented at the Annual Meeting of the American Educational Research Association, New Orleans, LA.

Slavin, R., \& Smith, D. (2009). The relationship between sample sizes and effect sizes in systematic reviews in education. Educational Evaluation and Policy Analysis, 31, 500506.

Steenkamp, J. E. M., de Jong, M. G., \& Baumgartner, H. (2010). Socially desirable responding tendencies in survey research. Journal of Marketing Research, 47, 199-214.

Steedle, J. T., Zahner, D., \& Kugelmass, H. (2014, April). Test administration procedures and their relationships with effort and performance on a college outcomes test. Paper presented at the annual meeting of the American Educational Research Association, Philadelphia, PA.

Sundre, D. L. (1996, April). The role of examinee motivation in assessment: Celebrity, scene stealer, or cameo? Paper presented at the annual meeting of the National Council on Measurement in Education, New York, NY. 
Sundre, D. L. (1997, April). Differential examinee motivation and validity: A dangerous combination. Paper presented at the annual meeting of the American Educational Research Association, Chicago, IL.

Sundre, D. L. (1999, April). Does examinee motivation moderate the relationship between test consequences and test performance? Paper presented at the annual meeting of the American Educational Research Association, Montreal, Quebec, Canada.

Sundre, D. L., \& Kitsantas, A. (2004). An exploration of the psychology of the examinee: Can examinee self-regulation and test-taking motivation predict consequential and nonconsequential test performance? Contemporary Educational Psychology, 29, 6-26.

Sundre, D. L., \& Moore, D. L. (2002). The Student Opinion Scale: A measure of examinee motivation. Assessment Update, 14, 8-9.

Swerdzewski, P. J., Harmes, J. C., \& Finney, S. J. (2011). Two approaches for identifying lowmotivated students in a low-stakes assessment context. Applied Measurement in Education, 24, 162-188.

Thelk, A. D., Sundre, D. L., Horst, S. J., \& Finney, S. J. (2009). Motivation matters: Using the Student Opinion Scale to make valid inferences about student performance. The Journal of General Education, 58, 129-151.

Tipton, E. (2015). Small sample adjustments for robust variance estimation with metaregression. Psychological Methods, 20, 375-393.

Truxillo, D. M., Bodner, T. E., Bertolino, M., Bauer, T. N., \& Yonce, C. A. (2009). Effects of explanations on applicant reactions: A meta-analytic review. International Journal of Selection, 17, 346-361.

UMass Donahue Institute (2011). Increasing student interest in science, technology, engineering, 
and math (STEM): Massachusetts STEM pipeline fund programs using promising practices. Hadley, MA: Author.

U.S. Department of Education (2013). Testing integrity symposium: Issues and recommendations for best practice. Washington D.C.: Author.

Voyer, D., \& Voyer, S. D. (2014). Gender differences in scholastic achievement: A metaanalysis. Psychological Bulletin, 140, 1174-1204.

Wainer, H. (1993). Measurement problems. Journal of Educational Measurement, 30, 1-21.

White, H. D. (2009). Scientific communication and literature retrieval. In H. Cooper, L. V. Hedges, and J. C. Valentine (Eds.), The Handbook of Research Synthesis and MetaAnalysis (2 ${ }^{\text {nd }}$ Ed.; pp. 51-72). New York, NY: Russell Sage Foundation.

Wigfield, A., \& Eccles, J. S. (2000). Expectancy-value theory of achievement motivation. Contemporary Educational Psychology, 25, 68-81.

Williams, L. M. (2015). The effect of examinee motivation on value-added estimates (unpublished doctoral dissertation). James Madison University: Harrisburg, VA.

Wise, S. L. (2006). An investigation of the differential effort received by items on a low-stakes computer-based test. Applied Measurement in Education, 19, 95-114.

Wise, S. L. (2014). The utility of adaptive testing in addressing the problem of unmotivated examinees. Journal of Computerized Adaptive Testing, 2, 1-18.

Wise, S. L., \& DeMars, C. E. (2005). Examinee motivation in low-stakes assessment: Problems and potential solutions. Educational Assessment, 10, 1-18.

Wise, S. L., \& DeMars, C. E. (2006). An application of item response time: The EffortModerated IRT Model. Journal of Educational Measurement, 43, 19-38.

Wise, S. L., \& DeMars, C. E. (2010). Examinee non-effort and the validity of program 
assessment results. Educational Assessment, 15, 27-41.

Wise, S. L., \& Kingsbury, G. G. (2016). Modeling student test-taking motivation in the context of an adaptive achievement test. Journal of Educational Measurement, 53, 86105.

Wise, S. L., Ma, L., Cronin, J., \& Theaker, R. A. (2013, April). Student test-taking effort and the assessment of student growth in evaluating teacher effectiveness. Paper presented at the annual meeting of the National Council on Measurement in Education, San Francisco, CA.

Wise, S. L., Pastor, D. A., \& Kong, K. J. (2009). Correlates of rapid-guessing behavior in lowstakes testing: Implications for test development and measurement practice. Applied Measurement in Education, 22, 185-205.

Wise, S. L., \& Smith, L. F. (2016). The validity of assessment when students don't give good effort. In G. T. L. Brown and L. R. Harris (Eds.), Handbook of Human and Social Conditions in Assessment (pp. 204-220). New York, NY: Routledge.

Wolf, L. F., \& Smith, J. K. (1995). The consequence of consequence: Motivation, anxiety, and test performance. Applied Measurement in Education, 8, 227-242.

Wolf, L. F., Smith, J. K., \& Birnbaum (1995). Consequence of performance, test, motivation, and mentally taxing items. Applied Measurement in Education, 8, 341-351.

Zilberberg, A., Brown, A. R., Harmes, J. C., \& Anderson, R. D. (2009). How can we increase student motivation during low-stakes testing? Understanding the student perspective. In D. M. McInerney, G. T. L. Brown, \& G. A. D. Liem (Eds.), Student perspectives on assessment: What students can tell us about assessment for learning (pp. 255-277). Greenwich, CT: Information Age Publishing. 
Table 1

Descriptive statistics for sample, methodological, assessment, and publication characteristics

\begin{tabular}{|c|c|c|c|c|c|c|c|c|c|c|c|c|c|}
\hline \multirow[b]{2}{*}{ Study Characteristics } & \multirow[b]{2}{*}{ Variable Type } & \multicolumn{6}{|c|}{ Test-Taking Effort } & \multicolumn{6}{|c|}{ Test Performance } \\
\hline & & $n$ & $\%$ & $M$ & $S D$ & $M d n$ & Range & $n$ & $\%$ & $M$ & $S D$ & $M d n$ & Range \\
\hline \multicolumn{14}{|l|}{ Sample } \\
\hline Average Sample Size & Continuous & 54 & --- & 675 & 1106 & 446 & $\begin{array}{l}62- \\
7011\end{array}$ & 105 & --- & 615 & 930 & 420 & $\begin{array}{l}25- \\
7011\end{array}$ \\
\hline Average Age in Years & Continuous & 51 & --- & 18.4 & 3.8 & 19 & $7-35$ & 93 & --- & 17.3 & 3.9 & 18 & $7-35$ \\
\hline$\%$ Postsecondary Samples ${ }^{\mathrm{a}}$ & Dichotomous & 54 & 69 & --- & --- & --- & $0-100$ & 105 & 57 & --- & --- & --- & $0-100$ \\
\hline$\%$ Female $^{\mathrm{b}}$ & Continuous & 48 & --- & 59 & 9 & 58 & $46-81$ & 80 & --- & 57 & 8 & 55 & $44-83$ \\
\hline$\%$ Majority White ${ }^{\mathrm{c}}$ & Dichotomous & 29 & 23 & --- & --- & --- & $0-100$ & 54 & 41 & --- & --- & --- & $0-100$ \\
\hline$\%$ U.S. Samples ${ }^{\mathrm{d}}$ & Dichotomous & 54 & 91 & --- & --- & --- & $0-100$ & 105 & 85 & --- & --- & --- & $0-100$ \\
\hline \multicolumn{14}{|l|}{ Method } \\
\hline$\%$ Randomization $^{\mathrm{e}}$ & Dichotomous & 54 & 78 & -- & --- & --- & $0-100$ & 105 & 74 & --- & --- & --- & $0-100$ \\
\hline$\%$ Mandatory Participation ${ }^{\mathrm{f}}$ & Dichotomous & 54 & 80 & --- & --- & --- & $0-100$ & 105 & 76 & --- & --- & --- & $0-100$ \\
\hline \multicolumn{14}{|l|}{ Assessment } \\
\hline Average Test Length & Continuous & 42 & --- & 51 & 17 & 44 & $20-108$ & 97 & --- & 46 & 30 & 42 & $1-175$ \\
\hline$\%$ Selected-Response Items ${ }^{\mathrm{g}}$ & Dichotomous & 45 & 80 & --- & --- & -- & $0-100$ & 101 & 73 & --- & --- & --- & $0-100$ \\
\hline$\%$ STEM Content ${ }^{\mathrm{h}}$ & Dichotomous & 45 & 82 & --- & --- & --- & $0-100$ & 105 & 67 & --- & --- & --- & $0-100$ \\
\hline \multicolumn{14}{|l|}{ Publication } \\
\hline \% Unpublished Studies & Dichotomous & 54 & 50 & --- & --- & --- & $0-100$ & 105 & 58 & --- & --- & --- & $0-100$ \\
\hline
\end{tabular}

Note. All values are rounded to integers; $n=$ number of unique study samples

aPercentage of samples in postsecondary education (coding: $0=\mathrm{K}-12$ sample; 1 = postsecondary sample).

bercentage of females in the total sample (combined experimental and control conditions).

'Percentage of sample that was White (coding: $0=<75 \%$ White; $1=\geq 75 \%$ White).

${ }^{\mathrm{d}}$ Percentage of samples that were collected within the United States (coding: $0=$ outside of the U.S., $1=$ within the U.S.).

ePercentage of studies that fully randomized samples into treatment conditions (coding: $0=$ quasi-randomized; $1=$ fully randomized).

fPercentage of studies requiring study participation (coding: $0=$ incentivized or voluntary participation; $1=$ mandatory participation).

gPercentage of studies that used a performance measure comprised solely of selected-response items (coding: $0=$ constructed-response or a mixture of constructed-response and selected-response items; 1 = solely selected-response items).

hPercentage of studies that used a performance measure comprised solely of STEM content (coding: $0=$ nonSTEM or a mixture of nonSTEM and STEM content; 1 = solely STEM content). 
Table 2

Differences in Effect Sizes Attributable to Moderators

\begin{tabular}{|c|c|c|c|c|c|c|}
\hline \multirow[t]{2}{*}{ Moderator } & \multicolumn{3}{|c|}{$\begin{array}{c}\text { Test-Taking Effort } \\
\quad(\mathrm{k}=28 ; \mathrm{n}=60)\end{array}$} & \multicolumn{3}{|c|}{$\begin{array}{c}\text { Test Performance } \\
(\mathrm{k}=49 ; \mathrm{n}=105)\end{array}$} \\
\hline & Estimate & S.E. & $95 \% \mathrm{CI}$ & Estimate & S.E. & $95 \% \mathrm{CI}$ \\
\hline Intercept $^{\mathrm{a}}$ & 0.10 & 0.10 & $-0.15,0.34$ & 0.21 & 0.20 & $-0.21,0.63$ \\
\hline \multicolumn{7}{|l|}{ Participant Characteristics } \\
\hline $\mathrm{Age}^{\mathrm{b}}$ & $0.14^{*}$ & 0.07 & $-0.03,0.31$ & $-0.13 *$ & 0.07 & $-0.27,0.01$ \\
\hline \multicolumn{7}{|l|}{ Methodological Considerations } \\
\hline Experimental Design $^{c}$ & 0.08 & 0.07 & $-0.08,0.23$ & -0.02 & 0.07 & $-0.17,0.13$ \\
\hline Recruitment Strategy ${ }^{\mathrm{d}}$ & $-0.34 * *$ & 0.08 & $-0.54,-0.14$ & -0.03 & 0.09 & $-0.21,0.15$ \\
\hline \multicolumn{7}{|l|}{ Assessment Design } \\
\hline Item Type e $^{\mathrm{e}}$ & --- & --- & --- & 0.17 & 0.10 & $-0.05,0.38$ \\
\hline Test Content $^{\mathrm{f}}$ & --- & --- & --- & 0.02 & 0.07 & $-0.12,0.16$ \\
\hline \multicolumn{7}{|l|}{ Publication Type $\mathrm{g}$} \\
\hline Grey Literature & $0.13 *$ & 0.06 & $0.00,0.26$ & 0.08 & 0.06 & $-0.05,0.21$ \\
\hline \multicolumn{7}{|l|}{ Intervention ${ }^{\mathrm{h}}$} \\
\hline Promising Feedback & -0.02 & 0.10 & $-0.26,0.023$ & $-0.22 *$ & 0.09 & $-0.42,-0.02$ \\
\hline Modifying Assessment Design & 0.16 & 0.11 & $-0.09,0.41$ & $-0.23 *$ & 0.10 & $-0.45,-0.01$ \\
\hline External Incentives & $0.37^{*}$ & 0.14 & $0.05,0.69$ & -0.13 & 0.12 & $-0.39,0.13$ \\
\hline
\end{tabular}

$* p<.05 ; * * p<.01$

Robust standard errors are provided in parentheses.

${ }^{a}$ The intercept is interpreted as the average effect size for independent samples that are published as grey literature, required mandatory participation in the intervention, employed a quasi-experimental design, included a K-12 sample, and employed the test relevance intervention.

${ }^{\mathrm{b}}$ Age was dichotomously coded (reference was $\leq 18$ years).

${ }^{\mathrm{c}}$ Experimental design was dichotomously coded (reference was quasi-experimental studies).

${ }^{\mathrm{d}}$ Recruitment strategy was dichotomously coded (reference was incentivized participation or volunteering).

'Item type was dichotomously coded (reference was constructed-response or mixed item format).

${ }^{\mathrm{f}}$ Test content was coded dichotomously (reference was non-STEM).

${ }^{\mathrm{g}}$ Grey literature was dichotomously coded (reference was grey literature).

${ }^{\mathrm{h}}$ The reference intervention was a mixture of promising feedback and combined approaches.

Based on a prior hypotheses, a one-tailed statistical test was employed for the following moderators: (a) age, (b) experimental design, (c) recruitment strategy, (d) item type, (e) test content, and (f) grey literature. 
Table 3

Unadjusted Average Effect Sizes by Intervention Type

\begin{tabular}{ccccccccc}
\hline & \multicolumn{3}{c}{ Test-Taking Effort } & \multicolumn{3}{c}{ Test Performance } \\
\hline Intervention Type & $n$ & $M$ & $S E$ & $95 \% C I$ & $n$ & $M$ & $S E$ & $95 \% C I$ \\
\hline Test Relevance & 12 & 0.21 & 0.16 & $-0.23,0.64$ & 25 & 0.27 & 0.08 & $0.09,0.46$ \\
Promising Feedback & 22 & -0.01 & 0.17 & $-0.83,0.80$ & 29 & 0.05 & 0.09 & $-0.32,0.43$ \\
Assessment Design & 17 & 0.13 & 0.17 & $-0.71,0.97$ & 28 & 0.06 & 0.09 & $-0.38,0.44$ \\
External Incentives & 9 & 0.36 & 0.17 & $-0.48,1.20$ & 23 & 0.21 & 0.12 & $-0.24,0.65$ \\
\hline
\end{tabular}

Note. The estimates presented do not account for moderators. $k=$ number of studies; $n=$ number of effect sizes; CI $=$ confidence interval. 

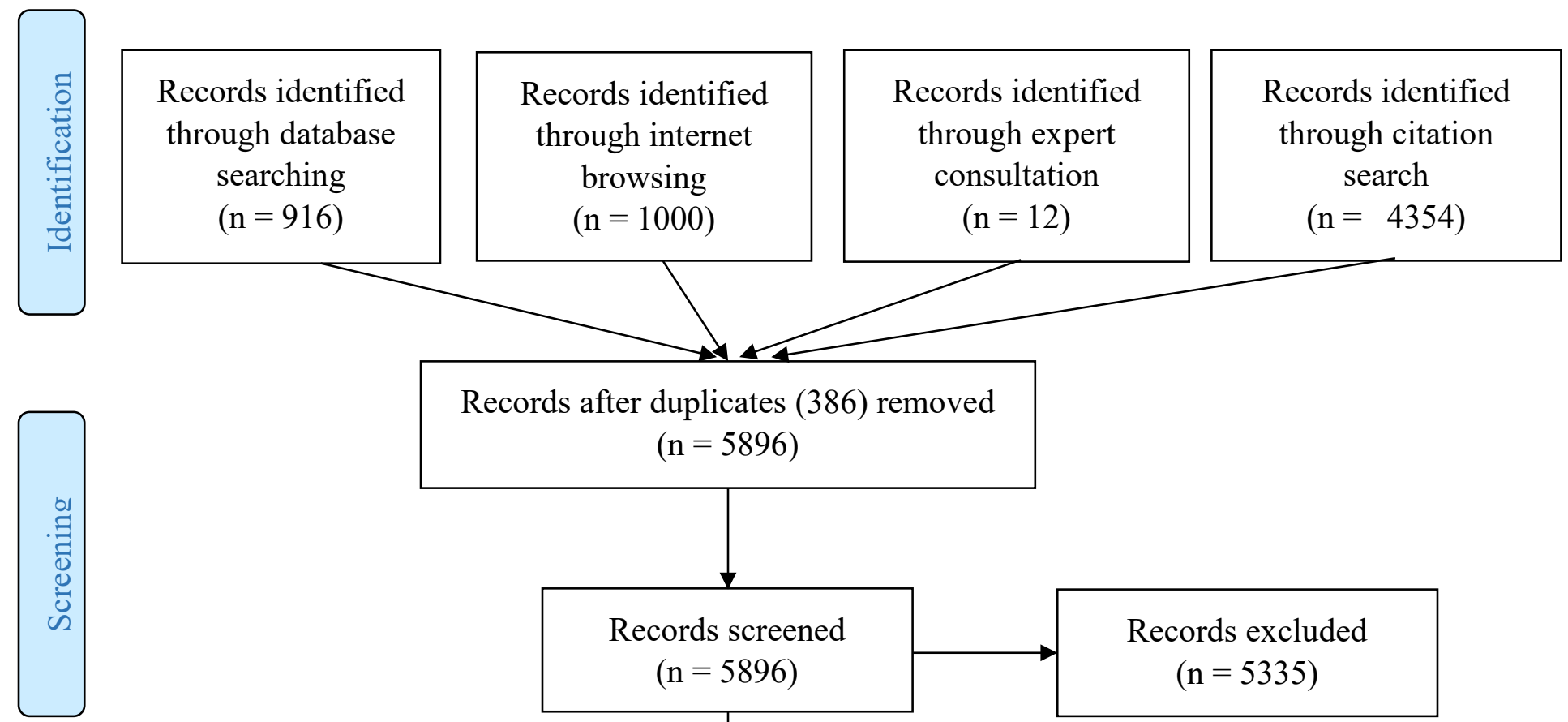

$$
\begin{aligned}
& \text { Records after duplicates (386) removed } \\
& \qquad(\mathrm{n}=5896)
\end{aligned}
$$

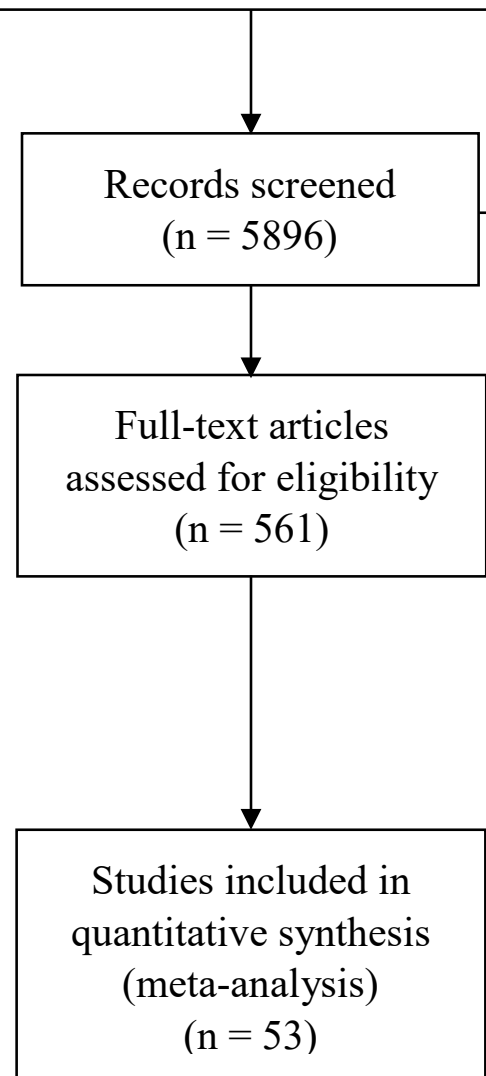

Figure 1. Flow chart of literature search strategies and results. Note that only 1,000 of the 2,860 articles found using internet browsing (Google Scholar) were accessible. The number of articles included in the meta-analysis for database searching, internet browsing, expert consultation, and citation searching was 16 (1.75\% hit rate), 15 (1.5\% hit rate), 9 (75\% hit rate), and 14 (0.32\% hit rate), respectively. 